\title{
Monodisperse $\mathrm{Fe}_{3} \mathrm{O}_{4}$ spheres: Large-scale controlled synthesis in the absence of surfactants and chemical kinetic process
}

\author{
Yana Li, Zhiyi Wang, Zeeshan Ali, Kesong Tian, Junjie Xu, Wei Li and Yanglong Hou*
}

\begin{abstract}
Fe}_{3} \mathrm{O}_{4}$ has attracted tremendous interest in vast areas of biomedicine and catalysis as well as environment engineering. However, it is highly desired to fully understand the chemical kinetic process and propose a general, surfactantfree, large-scale synthesis approach for $\mathrm{Fe}_{3} \mathrm{O}_{4}$ spheres. Herein, we developed a facile scalable solvothermal method in the absence of surfactants to produce $\mathrm{Fe}_{3} \mathrm{O}_{4}$ spheres with the yield of $5.1 \mathrm{~g}$, which present tunable sizes from 107 to $450 \mathrm{~nm}$ by modulated molar ratio of $\mathrm{Fe}^{3+} / \mathrm{COO}^{-}$in the solution. Particularly, it is observed that the reactants undergo a redox process, composed of a precipitation-dissolution equilibrium combined with a coordination reaction (termed as RPC), to the final product based on the LaMer model. It is worth noting that the generation of di-carboxyl group and its coordination with iron cations determine the formation of $\mathrm{Fe}_{3} \mathrm{O}_{4}$ spheres. This work not only offers a strategy to precisely tailor the particle size in scalable synthesis process, but also gives the insight on the role of dihydric alcohol in the formation mechanism of $\mathrm{Fe}_{3} \mathrm{O}_{4}$ spheres in the absence of surfactants.
\end{abstract}

Keywords: $\mathrm{Fe}_{3} \mathrm{O}_{4}$ spheres, surfactant-free, large-scale synthesis, chemical kinetic process

\section{INTRODUCTION}

$\mathrm{Fe}_{3} \mathrm{O}_{4}$ spheres have been intensively explored in the past few decades due to their unique electronic, magnetic and optical properties, which make them an ideal candidate for catalytic [1,2], biological [3-6] and photonics applications [7,8]. Multi-step self-assembly [9-12] and onestep solution growth [13-22] are main approaches for preparing $\mathrm{Fe}_{3} \mathrm{O}_{4}$ spheres [23], among which the one-step method is more flexible and efficient. Surfactants applied in the one-step solution growth process play a key role in regulating the morphology of $\mathrm{Fe}_{3} \mathrm{O}_{4}$ spheres and enhan- cing their stability, which affect adversely on the magnetic properties. For example, hydrophilic poly(acrylic acid) (PAA) [15] or trisodium citrate $\left(\mathrm{Na}_{3} \mathrm{Cit}\right)$ [14] are utilized to increase the interfacial hydrophilicity of $\mathrm{Fe}_{3} \mathrm{O}_{4}$, which eventually reduce the saturated magnetic moment $\left(M_{\mathrm{s}}\right)$ of $\mathrm{Fe}_{3} \mathrm{O}_{4}$ spheres. Thus, it is of great significance to develop a method to synthesize $\mathrm{Fe}_{3} \mathrm{O}_{4}$ spheres via surfactant-free approach.

Furthermore, understanding of the formation mechanism is an essential prerequisite for establishing the scope of synthesis of $\mathrm{Fe}_{3} \mathrm{O}_{4}$ spheres for broad applications. In previous studies [24-32], polyol has been widely employed as both solvent and reductant while either PAA or $\mathrm{Na}_{3}$ Cit is used as stabilizer. Cheng et al. [14] reported that the formation of $\mathrm{Fe}_{3} \mathrm{O}_{4}$ spheres depended on the balance of surface tension and electrostatic repelling forces of citrate molecules on the surface of nanocrystals. Recently, Gao's group [33] pointed that the crosslinking of the oxidized dihydric alcohols was responsible for forming $\mathrm{Fe}_{3} \mathrm{O}_{4}$ spheres. However, these mechanisms proposed in the presence of surfactant or stabilizer have not fully presented to us, reducing the reliability of the synthesis processes.

Herein, we developed a facile, scalable and surfactantfree polyol method to fabricate monodisperse $\mathrm{Fe}_{3} \mathrm{O}_{4}$ spheres whose size can be controlled by adjusting the molar ratio of $\mathrm{Fe}^{3+} / \mathrm{COO}^{-}$. Chemical reaction kinetics was further explored by an ex-situ time course study. A redox process, precipitation-dissolution equilibrium combined with a coordination reaction (termed as RPC) formation mechanism is proposed to describe the nucleation and growth process of $\mathrm{Fe}_{3} \mathrm{O}_{4}$ spheres. This mechanism is expected to open up a deep insight to precisely tailor the particle morphology with narrow size distribution in

Beijing Key Laboratory for Magnetoelectric Materials and Device (BKLMMD), Beijing Innovation Center for Engineering Science and Advanced Technology (BIC-ESAT), Department of Materials Science and Engineering, College of Engineering, Peking University, Beijing 100871, China

${ }^{*}$ Corresponding author (email: hou@pku.edu.cn) 
scalable synthesis process.

\section{EXPERIMENTAL SECTION}

\section{Chemicals}

All the raw materials were used without further purification. Iron(III) chloride hexahydrate $\left(\mathrm{FeCl}_{3} \cdot 6 \mathrm{H}_{2} \mathrm{O}\right.$, 99\%) and ethylene glycol (EG, 99\%) were purchased from Sinopharm Chemical Reagent Co., Ltd. Sodium acetate anhydrous $\left(\mathrm{CH}_{3} \mathrm{COONa}, \mathrm{NaAc}, 99 \%\right)$ was bought from Xi Long Chemical Co., Ltd, Guangdong, China.

\section{Synthesis of $\mathrm{Fe}_{3} \mathrm{O}_{4}$ spheres}

$\mathrm{Fe}_{3} \mathrm{O}_{4}$ spheres were synthesized by a modified solvothermal method referring to Li's method [13]. Firstly, $\mathrm{FeCl}_{3} \cdot 6 \mathrm{H}_{2} \mathrm{O}(1.35 \mathrm{~g})$ and $\mathrm{NaAc}(7.2 \mathrm{~g})$ were dissolved into $20 \mathrm{~mL}$ EG, respectively to form a homogeneous solution under magnetic stirring. Then $\mathrm{NaAc}$ (in EG solution) was added dropwise to $\mathrm{FeCl}_{3} \cdot 6 \mathrm{H}_{2} \mathrm{O}$ (in EG solution) with $1000 \mathrm{rpm}$ magnetic stirring for $1 \mathrm{~h}$. Subsequently, the obtained solution was sealed into a $50-\mathrm{mL}$ Teflon lined stainless autoclave. The autoclave reactor was then put into an oven and heated to $200^{\circ} \mathrm{C}$ and maintained for $6 \mathrm{~h}$ at that temperature. After cooling down to room temperature, the black sediments were collected and washed by deionized water or ethanol for three times to eliminate inorganic and organic impurities. By adjusting the molar ratio of $\mathrm{Fe}^{3+} / \mathrm{COO}^{-}$as $1 / 4.4,1 / 6.6,1 / 8.8,1 / 17.6,1 / 35.2$, 1/70.4, the obtained samples were named as $\mathrm{Fe}_{3} \mathrm{O}_{4}-i(i=$ $1-6)$.

To investigate the formation mechanism of $\mathrm{Fe}_{3} \mathrm{O}_{4}$ spheres, we monitored the reaction process after different reaction durations. The reactants were added using the above method with $\mathrm{Fe}^{3+} / \mathrm{COO}^{-}$molar ratio at $1 / 17.6$ and divided into six portions. Then these solutions were transferred to Teflon lined stainless autoclaves $(50 \mathrm{~mL})$ and reacted for $1,2,3,4,5,6 \mathrm{~h}$ at $200^{\circ} \mathrm{C}$, respectively. The obtained products were named as time- $i(i=1-6$, refered to the reaction time). In addition, the scalability of this technique was illustrated by carrying out the process using a 1-L Teflon lined stainless autoclave where twenty folds of the above reactants were employed.

\section{Characterizations}

The transmission electron microscopy (TEM) images were taken on an FEI Tecnai T20 TEM at an acceleration voltage of $200 \mathrm{kV}$, and the high resolution TEM (HRTEM) images were obtained on a Tecnai-G2-F30 (FEI) transmission electron microscope at $300 \mathrm{kV}$. Scanning electron microscopy (SEM) characterization was carried out using a Hitachi S-4800 scanning electron microscope. X-ray diffraction (XRD) studies were done by using a PAN analytical $\mathrm{X}^{\prime}$ Pert ${ }^{3}$ Powder X-ray diffractometer equipped with $\mathrm{Cu}-\mathrm{Ka}$ radiation $(40 \mathrm{kV}$, $40 \mathrm{~mA}$ ). XRD scan was performed in the $2 \theta$ range of $5^{\circ}$ $-85^{\circ}$. The FT-IR spectra were taken on PE-spotlight 200 FT-IR microscope with ATR attachment. X-ray photoelectron spectroscopy (XPS) characterization was investigated on Imaging Photoelectron Spectrometer (Axis Ultra DLD, Kratos Analytical Ltd.) with monochromatized $\mathrm{Al} \mathrm{Ka}$ radiation $(1486.6 \mathrm{eV})$ and chamber pressure at $10^{-8}-10^{-9}$ torr. The magnetic properties of the samples were recorded on a Physical Property Measurement System (PPMS, Dynacool, Quantum Design) at room temperature. The content of $\mathrm{Fe}_{3} \mathrm{O}_{4}$ was confirmed by inductively coupled plasma atomic emission spectroscopy (ICP-AES).

\section{RESULTS AND DISCUSSION}

\section{Characterization of $\mathrm{Fe}_{3} \mathrm{O}_{4}$ spheres with different sizes}

The $\mathrm{Fe}_{3} \mathrm{O}_{4}-i(i=1-6)$ spheres were produced by a facile solvothermal method with $\mathrm{Fe}^{3+} / \mathrm{COO}^{-}$molar ratio of 1/4.4, 1/6.6, 1/8.8, 1/17.6, 1/35.2, 1/70.4. In Fig. 1a-f, TEM images and the corresponding histograms show the spherical structures of $\mathrm{Fe}_{3} \mathrm{O}_{4}$-is $(i=1-6)$ with average diameters of $107,160,182,234,352$, and $450 \mathrm{~nm}$, respectively. The representative SEM images of the products are shown in Fig. 1g-1. As the molar ratio of $\mathrm{Fe}^{3+} / \mathrm{COO}^{-}$increased in the polyol reaction, the diameter of the resulting $\mathrm{Fe}_{3} \mathrm{O}_{4}$ spheres gradually increased from about 107 to $450 \mathrm{~nm}$, which was consistent with the TEM results.

The crystal structure and phase composition of the assynthesized products were confirmed by XRD analysis. In Fig. 2a, the columns at the bottom display the characteristic peaks of standard magnetite phase (PDF \#190629) [15]. It can be clearly observed that all the diffraction peaks of the $\mathrm{Fe}_{3} \mathrm{O}_{4}$-is are matched well with the standard PDF card, indicating that the products are pure $\mathrm{Fe}_{3} \mathrm{O}_{4}$. XPS analysis was further applied to confirm the valence state of $\mathrm{Fe}$ [34]. In Fig. 2b, the high-resolution $\mathrm{Fe} 2 \mathrm{p}$ spectrum of $\mathrm{Fe}_{3} \mathrm{O}_{4}-4$ consists of $\mathrm{Fe} 2 \mathrm{p}_{1 / 2}$ and $\mathrm{Fe} 2 \mathrm{p}_{3 / 2}$ at 724.3 and $710.6 \mathrm{eV}$, respectively [35]. Besides, the absence of the satellite peak at about $719.0 \mathrm{eV}$, which is the characteristic of $\mathrm{Fe}^{3+}$ in $\mathrm{Fe}_{2} \mathrm{O}_{3}$, affirms that the samples are composed of pure magnetite [36]. Furthermore, the HRTEM images of the $\mathrm{Fe}_{3} \mathrm{O}_{4}-4(234 \mathrm{~nm})$ in Fig. S1a, b show a lattice spacing of $0.296 \mathrm{~nm}$, corresponding to cubic magnetite (220) facet. It is worth 


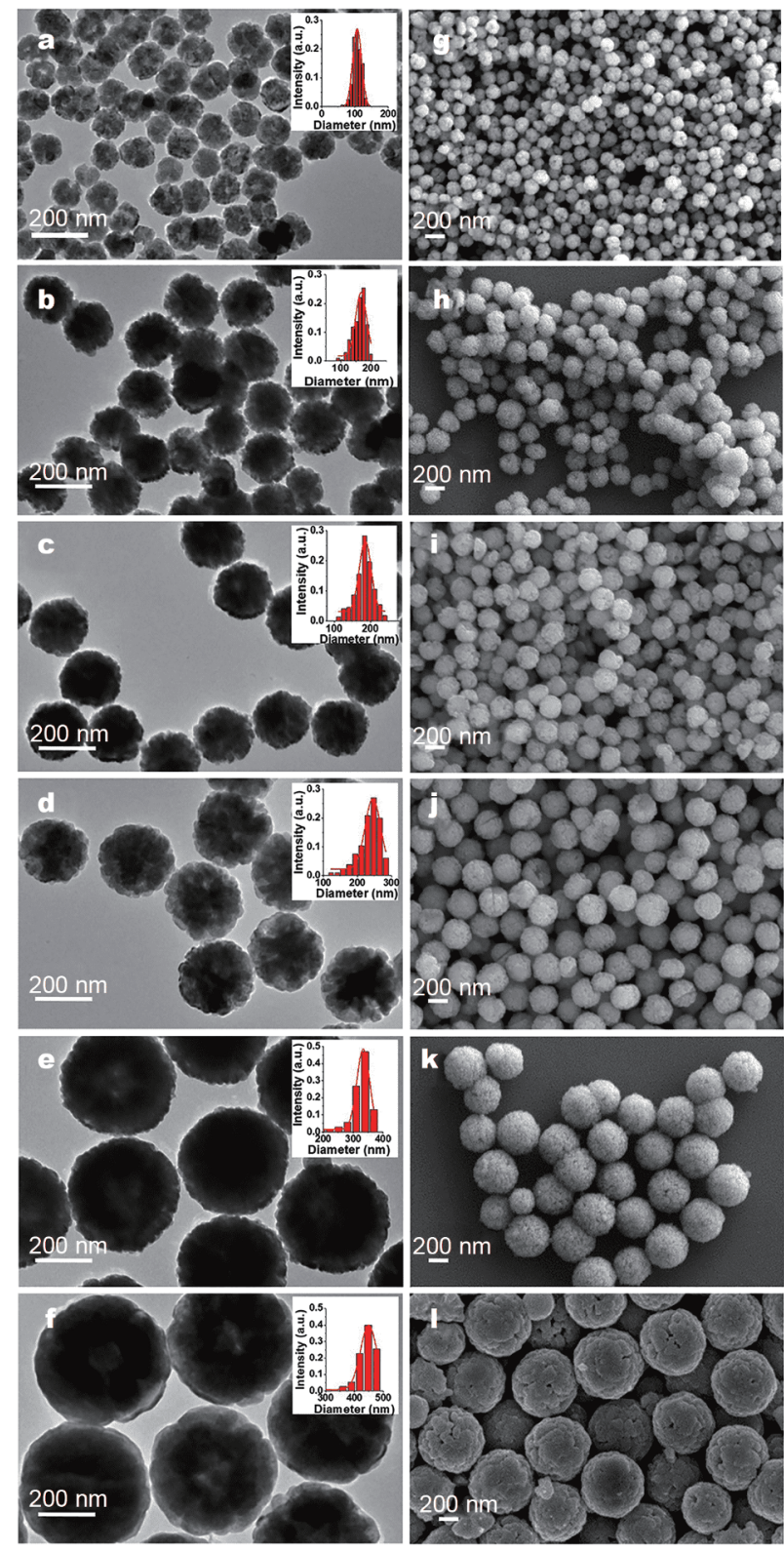

Figure 1 (a-f) TEM images and the corresponding histograms of the particle size distribution (inset images), (g-l) SEM images of the asprepared $\mathrm{Fe}_{3} \mathrm{O}_{4}-i$ spheres with molar ratio of $\mathrm{Fe}^{3+} / \mathrm{COO}^{-}$as $1 / 4.4,1 / 6.6$, $1 / 8.8,1 / 17.6,1 / 35.2,1 / 70.4$. The average sizes of spheres are $(\mathrm{a}, \mathrm{g})$ $107 \mathrm{~nm},(\mathrm{~b}, \mathrm{~h}) 160 \mathrm{~nm},(\mathrm{c}, \mathrm{i}) 182 \mathrm{~nm},(\mathrm{~d}, \mathrm{j}) 234 \mathrm{~nm},(\mathrm{e}, \mathrm{k}) 352 \mathrm{~nm}$, and (f, l) $450 \mathrm{~nm}$.

noting that the selected area electron diffraction (SAED) pattern of the $\mathrm{Fe}_{3} \mathrm{O}_{4}-4$ in Fig. S1c displays a polycrystalline structure, indicating misalignments among the primary nanocrystals. In Fig. S1d-f, energy dispersive spectrometer (EDS) chemical mapping images are also recorded to detect the elements distribution, which clearly displays that the product is composed of $\mathrm{Fe}$ and $\mathrm{O}$.
In order to explore the surface properties of the assynthesized $\mathrm{Fe}_{3} \mathrm{O}_{4}$ spheres, FT-IR and XPS analyses were further conducted. The FT-IR spectra (Fig. 2c) of $\mathrm{Fe}_{3} \mathrm{O}_{4}$ spheres show absorptions centered at 1557 and $1419 \mathrm{~cm}^{-1}$, which are attributed to the vibrations of the symmetric and asymmetric stretching of the $\mathrm{COO}^{-}$group [37]. Besides, the absorption peaks at $1044 \mathrm{~cm}^{-1}\left(v_{\text {as }}(\mathrm{C}-\right.$ $\mathrm{O}))$ and $885 \mathrm{~cm}^{-1}(\delta(\mathrm{O}-\mathrm{H}))$ reveal the existence of EG. Meanwhile, the products show strong absorption at $538 \mathrm{~cm}^{-1}$ owing to the $v(\mathrm{Fe}-\mathrm{O})$ of the magnetite spheres [38], which agrees well with the XRD and XPS analyses. The high-resolution $\mathrm{C} 1 \mathrm{~s}$ spectrum (Fig. S2a) of the $\mathrm{Fe}_{3} \mathrm{O}_{4}$ spheres displays three peaks at 288.7, 286.2 and $284.8 \mathrm{eV}$, corresponding to the aliphatic $-\mathrm{C}=\mathrm{O}$ groups, $-\mathrm{C}-\mathrm{OH}$ groups, and $-\mathrm{C}-\mathrm{C}$ bonds, respectively. The $\mathrm{O} 1$ s spectrum (Fig. S2b) displays three peaks at 531.2, 530.7 and $530.0 \mathrm{eV}$, which can be assigned to the oxygen in three different environments as $-\mathrm{O}-\mathrm{H}, \mathrm{O}-\mathrm{C}=\mathrm{O}$ and $\mathrm{Fe}-\mathrm{O}$, respectively $[4,36]$.

The magnetic properties of the $\mathrm{Fe}_{3} \mathrm{O}_{4}$ spheres were accessed by PPMS. The as-synthesized products exhibit super-paramagnetic behaviors at room temperature. And the saturation moments are found to be $76,79,81,83,85$ and $89 \mathrm{emu} \mathrm{g}^{-1}$ for $\mathrm{Fe}_{3} \mathrm{O}_{4}-i \quad(i=1-6)$, respectively (Fig. 2d). The values of $M_{\mathrm{s}}$ decrease slightly with the reduced sphere size, due to the lack of full alignment of the surface atoms and decreased crystallinity of the magnetite samples $[25,39]$. The element content of $\mathrm{Fe}$ in $\mathrm{Fe}_{3} \mathrm{O}_{4}-i$ was detected by ICP-AES analysis. It is found that the weight percentage of $\mathrm{Fe}_{3} \mathrm{O}_{4}-i(i=1-6)$ are more than $95 \%$, which is far beyond the ones with surfactant as reported $[14,19]$.

Furthermore, the scalable synthesis of the $\mathrm{Fe}_{3} \mathrm{O}_{4}$ spheres was also explored. $5.1 \mathrm{~g} \mathrm{Fe}_{3} \mathrm{O}_{4}$ spheres (Fig. S3b) with good dispersity (Fig. S3c) can be obtained at one time with 1-L Teflon lined stainless autoclaves (Fig. S3a). Besides, the crystallinity (Fig. S3d) and saturated moments (Fig. S3e) are almost the same as the product synthesized by $50-\mathrm{mL}$ Teflon lined stainless autoclaves, which demonstrates the scalability of this method.

\section{$E x$-situ chemical kinetic process exploration of $\mathrm{Fe}_{3} \mathrm{O}_{4}$ spheres}

The formation mechanism of the $\mathrm{Fe}_{3} \mathrm{O}_{4}$ spheres has been exploited by an $e x$-situ time study. TEM and SEM images of the products collected after different reaction times (time-i, $i=1-6$ ) are shown in Fig. 3 and Fig. S4. The TEM image of $1 \mathrm{~h}$ presents an aggregated granular morphology composed of tiny grains. Subsequently, sheet-like structure with a small amount of rough spherical particles (diameter of $40 \mathrm{~nm}$ ) emerged in Fig. 3b from the margin 

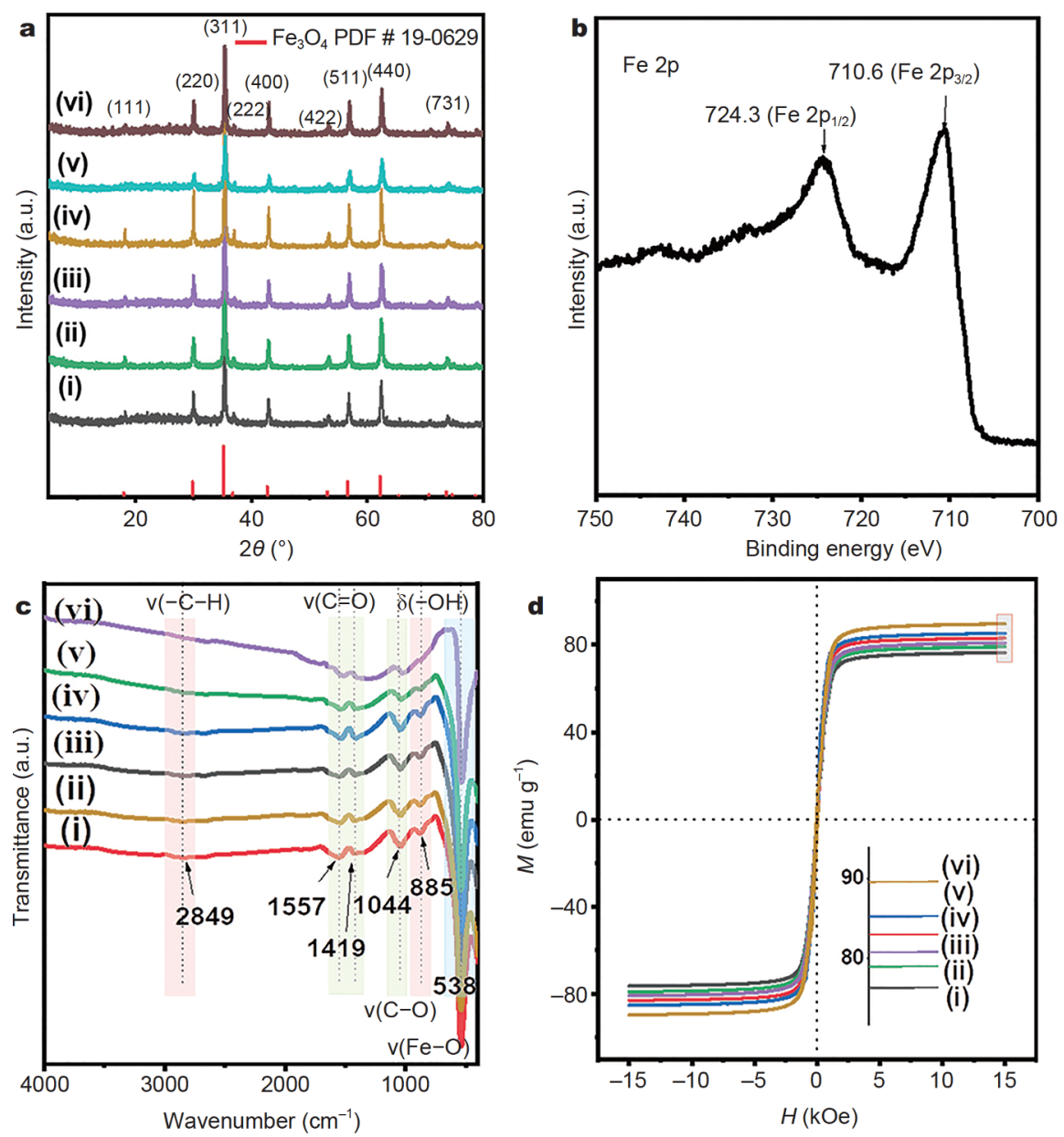

Figure 2 (a) XRD patterns, (b) XPS high-resolution of Fe 2p, (c) FT-IR spectra, (d) room-temperature magnetization curves. The samples were obtained by adjusting the molar ratio of $\mathrm{Fe}^{3+} / \mathrm{COO}^{-}$as (i) $1 / 4.4$, (ii) $1 / 6.6$, (iii) $1 / 8.8$, (iv) $1 / 17.6$, (v) $1 / 35.2$, (vi) $1 / 70.4$.

of the matrix. The content of sheet-like structure decreases while both of the amount and the diameter of the spherical particles increase (Fig. 3c, d). Consequently, the products display spherical particles without sheet-like structures, whose diameter increases slightly from $200 \mathrm{~nm}$ (Fig. 3e) to $230 \mathrm{~nm}$ (Fig. 3f). In addition, the HRTEM images of the product collected after $2 \mathrm{~h}$ reaction (time-2) in Fig. S5a and b display the lattice fringes of 0.296 and $0.216 \mathrm{~nm}$, corresponding to $\mathrm{Fe}_{3} \mathrm{O}_{4}$ (220) facet and $\mathrm{Fe}_{2} \mathrm{O}_{3}$ (101) facet. HRTEM image of the product in $2 \mathrm{~h}$ (Fig. S5b) shows an amorphous structure, which can be confirmed by SAED (Fig. S5c). This pre-aligned clusters were deemed as direct precursors of iron crystal and the alignment was hypothesized based on the anisotropic structural features within the short-range structure of the clusters [31].

Furthermore, the crystalline nature and the surface state of the ex-situ products were investigated via XRD and FT-IR. The XRD patterns of the isolated powders obtained after different durations are shown in Fig. 4a. The product obtained at $1 \mathrm{~h}$ presents strong peak at $21.2^{\circ}$, in accord with the (110) planes of FeOOH (PDF \#290731). As the time goes on, the dehydration of $\mathrm{FeOOH}$ starts and $\mathrm{FeOOH}$ transforms to $\mathrm{Fe}_{2} \mathrm{O}_{3} \cdot \mathrm{H}_{2} \mathrm{O}$ (PDF \#130092). The magnetite peaks are clearly detected at $4 \mathrm{~h}$, which indicates the products are the mixture of $\mathrm{Fe}_{2} \mathrm{O}_{3}$. $\mathrm{H}_{2} \mathrm{O}$ and $\mathrm{Fe}_{3} \mathrm{O}_{4}$. After $5 \mathrm{~h}$, the product completely transforms to well-crystallized $\mathrm{Fe}_{3} \mathrm{O}_{4}$ (PDF \#19-0629). Fig. $4 \mathrm{~b}$ shows the FT-IR-ATR spectra of the products prepared after different reaction times. At $1 \mathrm{~h}$ (time-1), the characteristic bands at about 1571 and $1444 \mathrm{~cm}^{-1}$ correspond to the symmetric and asymmetric stretching of the $\mathrm{COO}^{-}$group, coming from the absorption of NaAc. Meanwhile, the band at $1054 \mathrm{~cm}^{-1}$ is attributed to the C$\mathrm{O}$ stretching of $\mathrm{COO}^{-}$group. It is worth noting that the samples in Fig. 4b (ii-iv) show two obvious peaks at 2902 

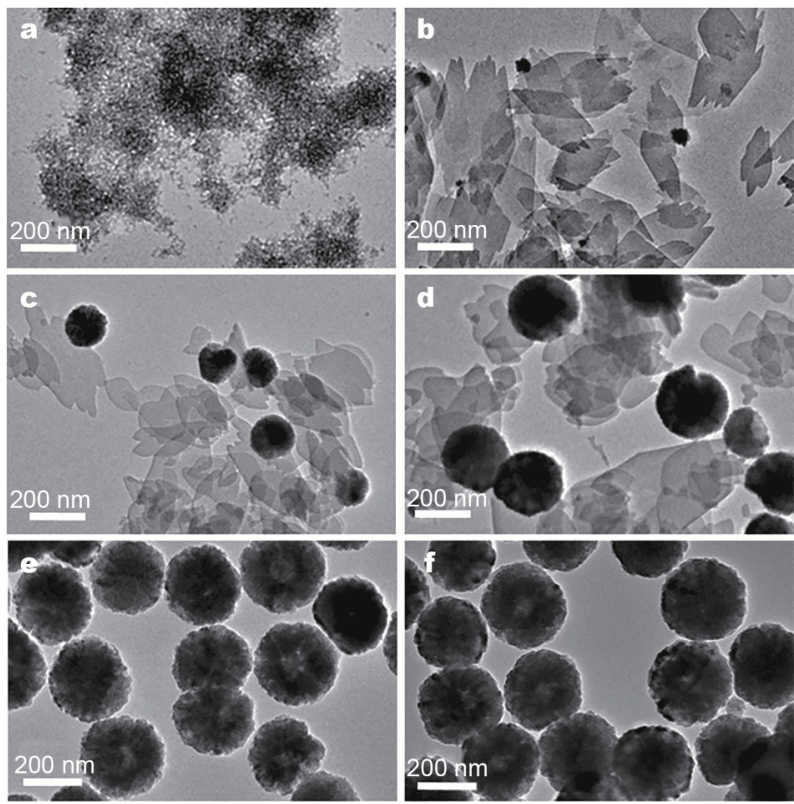

Figure 3 TEM images of the products prepared after different reaction durations: (a) 1, (b) 2, (c) 3, (d) 4, (e) 5, and (f) $6 \mathrm{~h}$.

and $2885 \mathrm{~cm}^{-1}$, which are assigned to the vibrations of the symmetric and asymmetric stretching of the $\mathrm{C}-\mathrm{H}$ group in aldehyde group, and the intensities of these signals decrease with time going on, demonstrating the glycol oxidation to glyoxal. In addition, the absorptions centered at 1535 and $1414 \mathrm{~cm}^{-1}$ in Fig. $4 \mathrm{~b}(\mathrm{v}, \mathrm{vi})$ are attributed to the vibration of $\mathrm{COO}^{-}$group. Particularly, the vibration band of $\mathrm{C}=\mathrm{O}$ shifts to lower wavenumber than Fig. $4 \mathrm{~b}-\mathrm{i}$ due to the formation of di-carboxyl group [33]. The absorption peaks at $1043 \mathrm{~cm}^{-1}\left(v_{\text {as }}(\mathrm{C}-\mathrm{O})\right)$ and $885 \mathrm{~cm}^{-1}$ $(\delta(\mathrm{O}-\mathrm{H}))$ reveal the existence of EG. Besides, the absorption band below $700 \mathrm{~cm}^{-1}$ is attributed to the vibration of $v(\mathrm{Fe}-\mathrm{O})$, and the peak at $537 \mathrm{~cm}^{-1}$ in Fig. $4 \mathrm{~b}(\mathrm{v}$, vi) indicates the formation of $\mathrm{Fe}-\mathrm{O}$ bond in $\mathrm{Fe}_{3} \mathrm{O}_{4}$ spheres.

\section{Formation mechanism of $\mathrm{Fe}_{3} \mathrm{O}_{4}$ spheres}

On the basis of the above analyses, it is evident that the transformation from glyoxal to oxalic acid and the coordination between $\mathrm{Fe}^{3+}$ and di-carboxyl in oxalic acid play an important role in forming magnetite spheres. The formation mechanism of magnetite spheres can be summarized as the following equilibriums:

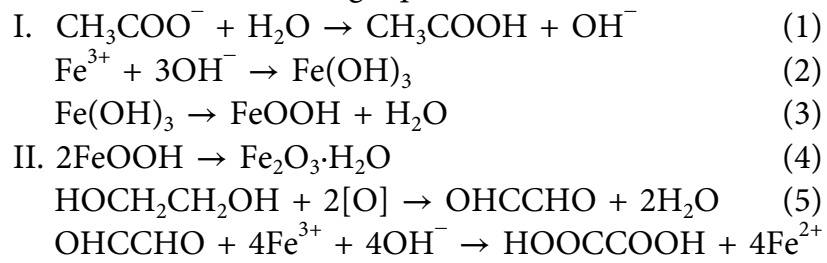

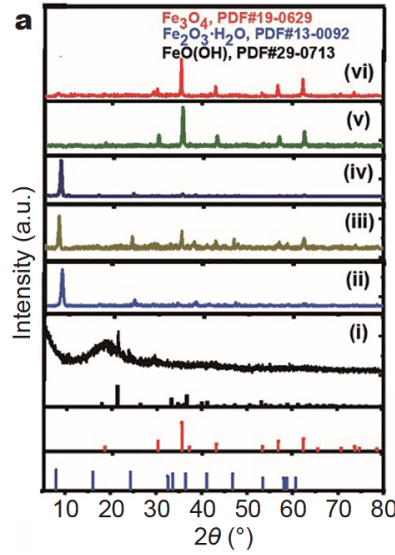

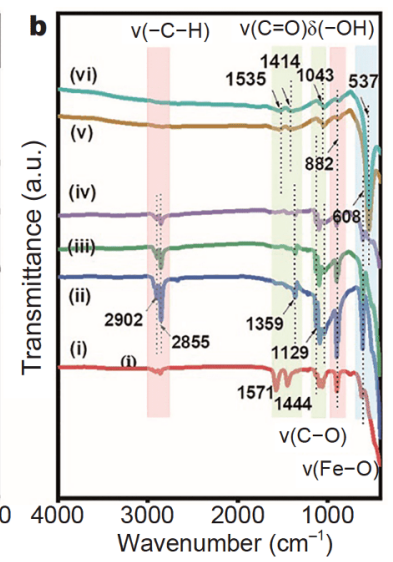

Figure 4 (a) XRD patterns and (b) FT-IR spectra of products prepared after different reaction durations: (i) 1, (ii) 2 , (iii) 3 , (iv) 4 , (v) 5 , and (vi) $6 \mathrm{~h}$.

$$
\begin{aligned}
& +2 \mathrm{H}_{2} \mathrm{O} \\
\text { III. } & \mathrm{Fe}^{2+}+2 \mathrm{OH}^{-} \rightarrow \mathrm{Fe}(\mathrm{OH})_{2} \\
& \mathrm{Fe}(\mathrm{OH})_{2}+2 \mathrm{Fe}(\mathrm{OH})_{3} \rightarrow \mathrm{Fe}_{3} \mathrm{O}_{4}+4 \mathrm{H}_{2} \mathrm{O} \\
& \mathrm{Fe}_{2} \mathrm{O}_{3} \cdot \mathrm{H}_{2} \mathrm{O}+\mathrm{Fe}(\mathrm{OH})_{2} \rightarrow \mathrm{Fe}_{3} \mathrm{O}_{4}+2 \mathrm{H}_{2} \mathrm{O} .
\end{aligned}
$$

At first, "self-nucleation" occurs at a rate called "effectively infinite" [24] according to LaMer model. Three main reactions are happening at this stage, which are, the hydrolysis of acetate (Equation (1)), the formation of $\mathrm{Fe}(\mathrm{OH})_{3}$ (Equation (2)) and $\mathrm{FeOOH}$ (Equation (3)). In stage II $(0.5-1.5 \mathrm{~h})$, there is a burst of nucleation of $\mathrm{Fe}_{2} \mathrm{O}_{3} \cdot \mathrm{H}_{2} \mathrm{O}$ through dehydration reaction of $\mathrm{FeOOH}$ (Equation (4)). At the same time, a redox process happens by oxidation of glycol (Equation (5)) and partial reduction of $\mathrm{Fe}(\mathrm{III})$ (Equation (6)), which is in agreement with the XRD and FT-IR analysis. In next stage (stage III), $\mathrm{Fe}(\mathrm{OH})_{2}$ forms (Equation (7)) and nucleation essentially stops. Meanwhile, $\mathrm{Fe}_{3} \mathrm{O}_{4}$ is formed through the reaction between $\mathrm{Fe}(\mathrm{OH})_{2}$ and $\mathrm{Fe}(\mathrm{OH})_{3}$ or $\mathrm{Fe}_{2} \mathrm{O}_{3} \cdot \mathrm{H}_{2} \mathrm{O}$ (Equations (8) and (9)). It should be noted that $\mathrm{Fe}_{3} \mathrm{O}_{4}$ nanoparticles grow to spheres structure by the strong coordination of iron cations and carboxylate group on the magnetite surface in the dissipation of pre-aligned $\mathrm{Fe}_{2} \mathrm{O}_{3} \cdot \mathrm{H}_{2} \mathrm{O}$ precursor. Finally, after a reaction of $6 \mathrm{~h}$, pure $\mathrm{Fe}_{3} \mathrm{O}_{4}$ spheres with high crystallinity are obtained. Particularly, the initial concentration of $\mathrm{FeCl}_{3} \cdot 6 \mathrm{H}_{2} \mathrm{O}$ in the solution plays a key role in the size control of the monodispersed $\mathrm{Fe}_{3} \mathrm{O}_{4}$ spheres via a precipitation-dissolution equilibrium. As the initial concentration of $\mathrm{Fe}^{3+}$ increases, the size of $\mathrm{Fe}_{3} \mathrm{O}_{4}$ spheres grows gradually. Thus, an RPC (refers to redox process, precipitation-dissolution equilibrium and coordination reaction, separately) mechanism based on LaMer model is proposed and schematically elaborated in Fig. 5. This scheme clearly depicts the redox reaction in 


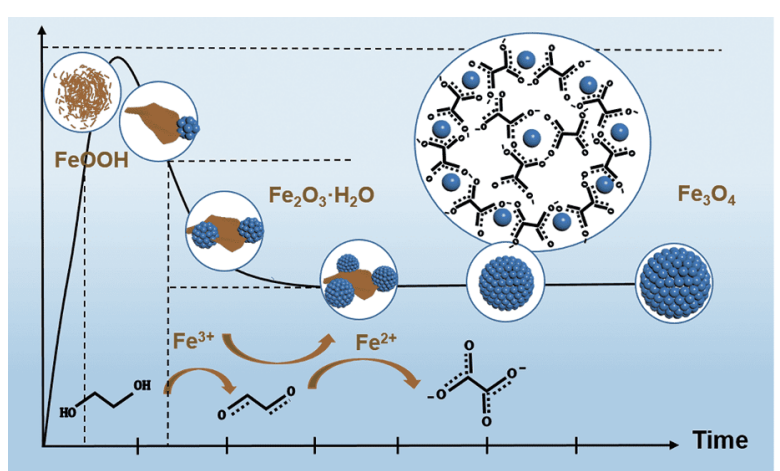

Figure 5 Schematic illustration of the formation mechanism of $\mathrm{Fe}_{3} \mathrm{O}_{4}$ spheres based on the laMer model.

the solution, the morphology evolution in solid state and the coordination structure of $\mathrm{Fe}^{3+}$ with di-carboxyl group over the process time.

$\mathrm{Fe}_{3} \mathrm{O}_{4}$ spheres have extraordinary catalytic activity, Li/ $\mathrm{Na}$ ion storage capability and biological applicability owing to their unique structure, magnetic proprieties and good biocompatibility [40-44]. In catalysis, $\mathrm{Fe}_{3} \mathrm{O}_{4}$ microspheres are ideal support materials as a result of their porous structure, rigid framework and short diffusion lengths of surrounding solutes, which ensure that the catalyst can maintain its original structure and catalytic activity [45-47]. Besides, in the biological field, microspheres can be conveniently separated from the solution mixture and the spheres is water-soluble, which is important for biomolecular separation, targeted drug delivery, hyperthermia treatment of cancer and magnetic resonance imaging [48-50].

\section{CONCLUSIONS}

In this work, we investigated the chemical kinetics of forming $\mathrm{Fe}_{3} \mathrm{O}_{4}$ spheres, which were obtained by a scalable surfactant-free solvothermal method. $\mathrm{Fe}_{3} \mathrm{O}_{4}$ spheres ranging from $107-450 \mathrm{~nm}$ can be addressed by tuning the molar ratio of $\mathrm{Fe}^{3+} / \mathrm{COO}^{-}$in the reaction solution. Furthermore, a RPC mechanism is proposed based on LaMer model and the coordination structure of di-carboxyl group with iron cations to interpret the nucleation and growth process of $\mathrm{Fe}_{3} \mathrm{O}_{4}$ spheres. This work figures out the formation mechanism of $\mathrm{Fe}_{3} \mathrm{O}_{4}$ spheres and offers a reliable synthetic method to produce large amount of $\mathrm{Fe}_{3} \mathrm{O}_{4}$ spheres for potential applications.

\section{Received 10 May 2019; accepted 26 June 2019;} published online 17 July 2019

1 Lee $\mathrm{SH}, \mathrm{Yu} \mathrm{SH}$, Lee JE, et al. Self-assembled $\mathrm{Fe}_{3} \mathrm{O}_{4}$ nanoparticle clusters as high-performance anodes for lithium ion batteries via geometric confinement. Nano Lett, 2013, 13: 4249-4256

2 Xiong QQ, Tu JP, Lu Y, et al. Synthesis of hierarchical hollowstructured single-crystalline magnetite $\left(\mathrm{Fe}_{3} \mathrm{O}_{4}\right)$ microspheres: the highly powerful storage versus lithium as an anode for lithium ion batteries. J Phys Chem C, 2012, 116: 6495-6502

3 Lee N, Choi SH, Hyeon T. Nano-sized CT contrast agents. Adv Mater, 2013, 25: 2641-2660

4 Shen LH, Bao JF, Wang D, et al. One-step synthesis of monodisperse, water-soluble ultra-small $\mathrm{Fe}_{3} \mathrm{O}_{4}$ nanoparticles for potential bio-application. Nanoscale, 2013, 5: 2133-2141

5 Kim D, Kwon HJ, Shin K, et al. Multiplexible wash-free immunoassay using colloidal assemblies of magnetic and photoluminescent nanoparticles. ACS Nano, 2017, 11: 8448-8455

6 Zhu K, Ju Y, Xu J, et al. Magnetic nanomaterials: Chemical design, synthesis, and potential applications. Acc Chem Res, 2018, 51: 404-413

7 Zhu M, Diao G. Synthesis of porous $\mathrm{Fe}_{3} \mathrm{O}_{4}$ nanospheres and its application for the catalytic degradation of xylenol orange. J Phys Chem C, 2011, 115: 18923-18934

8 Dong Y, Wen B, Chen Y, et al. Autoclave-free facile approach to the synthesis of highly tunable nanocrystal clusters for magnetic responsive photonic crystals. RSC Adv, 2016, 6: 64434-64440

9 Bai F, Wang D, Huo Z, et al. A versatile bottom-up assembly approach to colloidal spheres from nanocrystals. Angew Chem Int Ed, 2007, 46: 6650-6653

10 Paquet C, Page L, Kell A, et al. Nanobeads highly loaded with superparamagnetic nanoparticles prepared by emulsification and seeded-emulsion polymerization. Langmuir, 2010, 26: 5388-5396

11 Toprak M, McKenna B, Mikhaylova M, et al. Spontaneous assembly of magnetic microspheres. Adv Mater, 2007, 19: 1362-1368

12 Zhuang J, Wu H, Yang Y, et al. Controlling colloidal superparticle growth through solvophobic interactions. Angew Chem Int Ed, 2008, 47: 2208-2212

13 Deng H, Li X, Peng Q, et al. Monodisperse magnetic single-crystal ferrite microspheres. Angew Chem, 2005, 117: 2842-2845

14 Cheng $\mathrm{C}$, Wen $\mathrm{Y}, \mathrm{Xu} \mathrm{X}$, et al. Tunable synthesis of carboxylfunctionalized magnetite nanocrystal clusters with uniform size. J Mater Chem, 2009, 19: 8782

15 Liu J, Sun Z, Deng Y, et al. Highly water-dispersible biocompatible magnetite particles with low cytotoxicity stabilized by citrate groups. Angew Chem, 2009, 121: 5989-5993

16 Hao R, Xing R, Xu Z, et al. Synthesis, functionalization, and biomedical applications of multifunctional magnetic nanoparticles. Adv Mater, 2010, 22: 2729-2742

$17 \mathrm{Ge} \mathrm{J}, \mathrm{Hu} \mathrm{Y}$, Biasini M, et al. Superparamagnetic magnetite colloidal nanocrystal clusters. Angew Chem Int Ed, 2007, 46: 4342-4345

$18 \mathrm{Ge}$ J, Hu Y, Biasini M, et al. One-step synthesis of highly watersoluble magnetite colloidal nanocrystals. Chem Eur J, 2007, 13: 7153-7161

19 Xuan S, Wang YXJ, Yu JC, et al. Tuning the grain size and particle size of superparamagnetic $\mathrm{Fe}_{3} \mathrm{O}_{4}$ microparticles. Chem Mater, 2009, 21: 5079-5087

20 Dong F, Guo W, Bae JH, et al. Highly porous, water-soluble, superparamagnetic, and biocompatible magnetite nanocrystal clusters for targeted drug delivery. Chem Eur J, 2011, 17: 12802-12808

21 Xuan S, Wang F, Wang YXJ, et al. Facile synthesis of size-controllable monodispersed ferrite nanospheres. J Mater Chem, 2010, 20: 5086

22 Gao J, Ran X, Shi C, et al. One-step solvothermal synthesis of highly water-soluble, negatively charged superparamagnetic $\mathrm{Fe}_{3} \mathrm{O}_{4}$ 
colloidal nanocrystal clusters. Nanoscale, 2013, 5: 7026-7033

23 Lu Z, Yin Y. Colloidal nanoparticle clusters: Functional materials by design. Chem Soc Rev, 2012, 41: 6874-6887

24 Finney EE, Finke RG. Nanocluster nucleation and growth kinetic and mechanistic studies: A review emphasizing transition-metal nanoclusters. J Colloid Interface Sci, 2008, 317: 351-374

25 Fan T, Pan D, Zhang H. Study on formation mechanism by monitoring the morphology and structure evolution of nearly monodispersed $\mathrm{Fe}_{3} \mathrm{O}_{4}$ submicroparticles with controlled particle sizes. Ind Eng Chem Res, 2011, 50: 9009-9018

26 Shen W, Chen X, Shi Y, et al. Synthesis of monodisperse and single-crystal $\mathrm{Fe}_{3} \mathrm{O}_{4}$ hollow spheres by a solvothermal approach. Mater Chem Phys, 2012, 132: 987-992

27 Cha J, Lee JS, Yoon SJ, et al. Solid-state phase transformation mechanism for formation of magnetic multi-granule nanoclusters. RSC Adv, 2013, 3: 3631

28 Lin $\mathrm{M}$, Huang $\mathrm{H}$, Liu $\mathrm{Z}$, et al. Growth-dissolution-regrowth transitions of $\mathrm{Fe}_{3} \mathrm{O}_{4}$ nanoparticles as building blocks for 3D magnetic nanoparticle clusters under hydrothermal conditions. Langmuir, 2013, 29: 15433-15441

29 Nguyen DT, Kim KS. Analysis on development of magnetite hollow spheres through one-pot solvothermal process. AIChE J, 2013, 59: 3594-3600

30 Qiao L, Swihart MT. Solution-phase synthesis of transition metal oxide nanocrystals: Morphologies, formulae, and mechanisms. Adv Colloid Interface Sci, 2017, 244: 199-266

31 Sun S, Gebauer D, Cölfen H. Alignment of amorphous iron oxide clusters: A non-classical mechanism for magnetite formation. Angew Chem Int Ed, 2017, 56: 4042-4046

32 Yang $\mathrm{C}, \mathrm{Wu}$, Hou Y. $\mathrm{Fe}_{3} \mathrm{O}_{4}$ nanostructures: Synthesis, growth mechanism, properties and applications. Chem Commun, 2011, 47: 5130-5141

33 Wei X, Jing L, Liu C, et al. Molecular mechanisms for delicately tuning the morphology and properties of $\mathrm{Fe}_{3} \mathrm{O}_{4}$ nanoparticle clusters. CrystEngComm, 2018, 20: 2421-2429

34 Zhong LS, Hu JS, Liang HP, et al. Self-assembled 3D flowerlike iron oxide nanostructures and their application in water treatment. Adv Mater, 2006, 18: 2426-2431

35 Grosvenor AP, Kobe BA, Biesinger MC, et al. Investigation of multiplet splitting of Fe 2p XPS spectra and bonding in iron compounds. Surf Interface Anal, 2004, 36: 1564-1574

36 Yamashita T, Hayes P. Analysis of XPS spectra of $\mathrm{Fe}^{2+}$ and $\mathrm{Fe}^{3+}$ ions in oxide materials. Appl Surf Sci, 2008, 254: 2441-2449

37 Chen F, Zhao T, Chen Q, et al. Size-controlled monodisperse hydrophobic and hydrophilic magnetite nanoparticles: One-pot synthesis, characterization, and the mechanism study. Mater Res Bull, 2013, 48: 4093-4099

38 Ferraro JR, Driver R, Walker WR, et al. Infrared spectra of several hydroxy-bridged complexes of chromium(III) and iron(III) from 650 to $80 \mathrm{~cm}^{-1}$. Inorg Chem, 1967, 6: 1586-1588

39 Ganesan V, Louis C, Damodaran SP. Novel nanofluids based on magnetite nanoclusters and investigation on their cluster sizedependent thermal conductivity. J Phys Chem C, 2018, 122: 69186929
40 Yu Y, Mendoza-Garcia A, Ning B, et al. Cobalt-substituted magnetite nanoparticles and their assembly into ferrimagnetic nanoparticle arrays. Adv Mater, 2013, 25: 3090-3094

41 Han G, Li M, Yu Y, et al. Structure and magnetic properties of cobalt ferrite foam with low mass density. J Alloys Compd, 2019, 790: 947-954

42 Li M, Yang W, Huang Y, et al. Hierarchical mesoporous $\mathrm{Co}_{3} \mathrm{O}_{4} @$ $\mathrm{ZnCo}_{2} \mathrm{O}_{4}$ hybrid nanowire arrays supported on Ni foam for highperformance asymmetric supercapacitors. Sci China Mater, 2018, 61: $1167-1176$

43 Li M, Yang W, Li J, et al. Porous layered stacked $\mathrm{MnCo}_{2} \mathrm{O}_{4}$ cubes with enhanced electrochemical capacitive performance. Nanoscale, 2018, 10: 2218-2225

44 Yang W, Yu Y, Wang L, et al. Controlled synthesis and assembly into anisotropic arrays of magnetic cobalt-substituted magnetite nanocubes. Nanoscale, 2015, 7: 2877-2882

45 Wang Y, Li M, Xu L, et al. Polar and conductive iron carbide@Ndoped porous carbon nanosheets as a sulfur host for high performance lithium sulfur batteries. Chem Eng J, 2019, 358: 962-968

46 Papadas IT, Vamvasakis I, Tamiolakis I, et al. Templated selfassembly of colloidal nanocrystals into three-dimensional mesoscopic structures: a perspective on synthesis and catalytic prospects. Chem Mater, 2016, 28: 2886-2896

47 Ali Z, Tang T, Huang X, et al. Cobalt selenide decorated carbon spheres for excellent cycling performance of sodium ion batteries. Energy Storage Mater, 2018, 13: 19-28

48 Zhang $\mathrm{H}$, Li L, Liu XL, et al. Ultrasmall ferrite nanoparticles synthesized via dynamic simultaneous thermal decomposition for high-performance and multifunctional $T_{1}$ magnetic resonance imaging contrast agent. ACS Nano, 2017, 11: 3614-3631

49 Zhou Z, Tian R, Wang Z, et al. Artificial local magnetic field inhomogeneity enhances $T_{2}$ relaxivity. Nat Commun, 2017, 8: 15468-15478

50 Ling D, Lee N, Hyeon T. Chemical synthesis and assembly of uniformly sized iron oxide nanoparticles for medical applications. Acc Chem Res, 2015, 48: 1276-1285

Acknowledgements This work was financially supported by the National Natural Science Foundation of China (51631001, 51672010 and $81421004)$, and the National Key R\&D Program of China (2017YFA0206301 and 2016YFA0200102).

Author contributions Li Y performed the experiments and wrote the draft of manuscript; Li Y and Wang $\mathrm{Z}$ conceived the idea and analyzed the data; Ali Z, Tian K, Xu J and Li W provided some additional suggestions and comments on analyzing the data and the manuscript; Hou $\mathrm{Y}$ proposed the project and revised the manuscript. All authors contributed to the general discussion and checked the manuscript.

Conflict of interest The authors declare that they have no conflict of interest.

Supplementary information

Supporting data are available in the online version of the paper. 


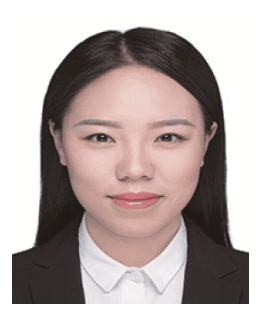

Yana Li received her BSc degree from Sichuan University in 2016. Currently, she is a master candidate at Peking University. Her current research interest focuses on the synthesis of magnetic nanomaterials.

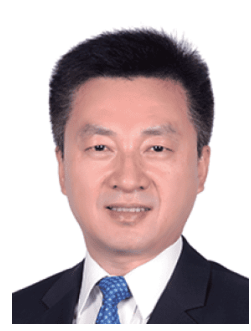

Yanglong Hou received his $\mathrm{PhD}$ in materials science from Harbin Institute of Technology (China) in 2000. After a short postdoctoral training at Peking University, he worked at the University of Tokyo from 2002 to 2005 as a JSPS foreign special researcher and also at Brown University from 2005 to 2007 as a postdoctoral researcher. He joined Peking University in 2007, and now is a Professor of Materials Science. His research interests include the design and chemical synthesis of functional nanoparticles and graphene, and their biomedical and energy-related applications.

\section{无表面活性剂条件下大规模可控制备单分散 $\mathrm{Fe}_{3} \mathrm{O}_{4}$ 及其化学动力学过程研究}

李雅娜, 汪志义, Zeeshan Ali, 田克松, 徐俊杰, 李巍, 侯仰龙 ${ }^{*}$

摘要 $\mathrm{Fe}_{3} \mathrm{O}_{4}$ 微球被广泛应用于生物医药、催化和环境工程领域. 理解 $\mathrm{Fe}_{3} \mathrm{O}_{4}$ 微球的化学动力学过程并发展一种通用的、无表面活性 剂的大规模合成 $\mathrm{Fe}_{3} \mathrm{O}_{4}$ 微球的方法成为当前的迫切需求. 本文提出 了一种简单的无表面活性剂的方法用于大规模合成 $\mathrm{Fe}_{3} \mathrm{O}_{4}$ 微球，通 过调节溶液中 $\mathrm{Fe}^{3+} / \mathrm{COO}^{-}$的比例, 合成了直径为 107 到 $450 \mathrm{~nm}$ 的 $\mathrm{Fe}_{3} \mathrm{O}_{4}$ 微球. 研究表明, 反应物通过氧化还原反应、沉淀溶解平衡 和配位过程形成最终反应产物. 其中，二羧基基团和铁离子的配位 促进了 $\mathrm{Fe}_{3} \mathrm{O}_{4}$ 微球的形成. 本文不仅提供了一种在大规模合成反应 过程中调控产物尺寸的方法, 而且详细研究了在无表面活性剂条 件下合成 $\mathrm{Fe}_{3} \mathrm{O}_{4}$ 微球过程中醇起到的特殊作用. 